\title{
Path Ahead for Public Sector Engineers
}

\author{
Janaka Seneviratne
}

\begin{abstract}
Sri Lanka is blessed with high calibre, technically competent engineers. However, the lack of proper administrative and regulatory systems in the country is cited as the main reason for the lacklustre performance of its public sector engineers.
\end{abstract}

Engineers have to think differently, act more proactively and try out new processes and procedures to ensure that the organisations where they work are service centric and socially responsive.

Public sector engineers have to be aware of their own limitations and should seek external guidance whenever necessary. Local engineers can make use of international concepts, methodologies, guidelines, codes of practice and tools towards this end.

Strategic planning processes in the public sector organisations need radical changes. Engineers should apply the 'systems view concept' holistically to assess the effectiveness of the management structure of their organisations. The organisational culture needs to be enriched with consultative decision making processes and teamwork. The Institution of Engineers, Sri Lanka (IESL) has to act as a facilitator in this process. The ultimate aim should be to embrace business excellence elements to be an integral part of each organisation concerned.

Keywords: Administrative and Regulatory Systems, Systems View, Business Excellence Framework, Organisation Culture, Different Thinking

\section{Public Sector Engineers}

The author of this article is an engineer who has worked in the public sector in Sri Lanka as well as overseas. Hence, the author has a professional interest to express his opinion on the performance of the Sri Lankan engineers and also on the engineering profession.

The scope of this article has been confined to the role of Sri Lankan engineers employed in government and semi-government sectors.

The public sector engineers are the backbone of the engineering profession in Sri Lanka. The Sri Lankan engineering sector has been shaped by them and the Sri Lankan economy which is deficient in infrastructure is being revived by them. Hence, it is reasonable to say that they are the engineering role models.

Is there any established method to determine whether an engineer is good, average or bad?

Of course, any engineer who has successfully completed a formally recognised study program will be able to technically perform as an engineer. However, his/her performance has to be measured in terms of his/her ability to initiate and make use of system improvements, apply skills, knowledge and experience within a volatile and demanding work environment.
Hence, how good or bad an engineer is determined through the measurement of specifically developed Key Performance Indicators (KPIs) rather than by counting his/her academic qualifications and the number of years he/she has been employed.

Do Sri Lankan public sector engineers fulfil the public expectations of them? More precisely, are they allowed to perform the way they would like to perform?

According to the author's own experience and exposure to both environments, there is a vast disparity between the performance of Sri Lankan engineers when they are based in Sri Lanka and that when they based overseas.

There is a widely known public perception that public sector engineers underperform and they fail to meet the public expectations. The author believes that the lack of transparency and consistency in the dealings of the engineers in Sri Lanka are the main reasons for this unfortunate public perception about them. It is startling to witness how public sector engineers branded as under-performers in Sri

Eng. Janaka Seneviratne, C.Eng, MIE(Sri Lanka), B.Sc.

(Eng), MEng (Local Gov. Eng.), MEng (Eng Mgt), MEA

(Australia), Team Coordinator-Buildings Team, Canterbury

Bankstown City Council, NSW, Australia.

Email:senevir15@gmail.com 
Lanka, perform remarkably well when they work in foreign countries. This proves that there is nothing wrong with the capabilities of the public sector engineers in Sri Lanka, but that it is the local conditions that compel them to perform the way they do at present.

\section{Elements of a Healthy Organisation}

The author has participated in numerous overseas workshops and training programs and through them has gathered an intimate knowledge on the basic features of a healthy organisational setup which allows staff to perform well, unlocking their full potential.

The main features of such a set up are as follows:

1. Well developed systems and sub systems, promoting synchronised operation

2. Processes and procedures covering all duties, responsibilities and accountabilities to eliminate overlaps and conflicts

3. Competent staff with necessary skills, knowledge, experience and educational qualifications, in that order of importance

4. A set of Key Performance Indicators (KPIs)

5. A mechanism to address KPI benchmark issues

This paper draws the attention of readers only to Item 1 above as the author believes that all other items listed above also need in-depth analysis. The author therefore intends to write separate articles on each of them in the future, depending on the readers' feedback.

\section{Initial Focus}

The performance disparity of public sector engineers relates to the differences between Sri Lanka and developed countries in the regulatory and administrative systems, processes and procedures they adopt.

The improved performance of the Sri Lankan engineers when they are overseas is a direct result of the way they acknowledge workplace freedom; value the encouragement and support they receive from peers and senior management; and fit into the culture of their respective organisations while being satisfied for becoming a part of a well organised work set up and decision making process.

The engineers in Sri Lanka would certainly wish for similar conditions to prevail at their own workplaces.

Hence, it is high time to develop such work environments to enable Sri Lankan engineers also to work at their full potential while being still a part of the Sri Lankan work force. It is important to realise that unless public sector engineers in Sri Lanka themselves understand the problems they face and make the initial move and express their keenness to find solutions, no one from outside would come forward to help them.

This is not about implementing a one-off project but is about starting on a long journey. So, engineers need to brace themselves for a long haul. There is also no end-date to this journey. It is an endeavour that should be continued forever, with short-term milestones and a long term vision.

There are two ways to go on this journey.

One can start the journey from scratch, by literally developing tools and guides, planning the route and deciding on milestones.

The other option would be to borrow someone else's well tested route plan, tools and guides and then rebrand them to suit the local appeal, switch on appropriate features, set warning alarms to alert when the plan deviates from the set path and reach the destination, while celebrating the achievements on the way.

Sri Lankan engineers have wasted a great deal of their time, trying to build their own tools and guides. Now, it is the time to borrow someone else's vehicle.

There are many plans and tools elsewhere and the time is right to borrow and utilise them.

\section{Importance of the Socio- Engineering Aspects}

In general, our engineers perform well when working in foreign environments. There is ample evidence and conferred accolades which endorse this claim.

However, this does not mean that all were high performers at the beginning itself. The 
problems they faced initially were essentially due to the repercussions of the theory based education system and hierarchical and bullish work cultures prevalent in Sri Lanka. Some still struggle to keep their feet firm on foreign public workplaces. Many Sri Lankan engineers who had placed heavy emphasis on technical skills development and authoritative management styles were unable to fit into the socio-engineering work environments of the foreign countries. It is those who had previously served as senior public sector engineers who faced this adaptation issue most.

In developed countries, public sector engineers develop technical outputs and then transform these outputs into easy-to-understand, practically implementable outputs. This strategy caters to the general public who lack technical knowledge.

To reach out to stakeholders skilfully, engineers have to utilise a range of skills and tools such as simple language, creative writing, clear and concise communications and userfriendly presentations. Technical skills alone will not be sufficient for the engineers to perform well.

In general, our engineers love complicated analyses and cumbersome, heavily-worded technical reports. Of course, this skill is well recognised in Sri Lanka as a symbol of academic excellence, competence and authority. Our culture frowns upon simple English and concise reports considering them as substandard products.

In Western countries, unbalanced technical emphasis on decision making and writing of bulky and long-winded reports are seen as unnecessary consultation tools.

Sri Lankans are fond of telling, writing and reading stories. Some Sri Lankan engineers overuse this habit.

We all love to talk about the ancient glory of Sri Lanka and the achievements of our ancestors. There is certainly nothing wrong in appreciating ancient engineering marvels. Also, it is not wrong to document past mistakes. However, both these actions will ring hollow, if engineers do not apply lessons learnt from the history and from previous mistakes, to make better the present and the future.
Foreign administrators support the celebration of past victories but encourage the engineers to focus more on the application of new technologies to avoid the repetition of past mistakes.

Administrators expect engineers to produce written, concise reports in a simple and easy to understand language to support their recommendations, addressing the target audience specifically.

In the developed world, everyone is socially equal. Irrespective of whether one is a staff member, an engineer, a director or a cleaner, he/she will be addressed by first name and will have an equal "say" and "treatment" as the rest in the organisation.

Importantly, all are members of a dedicated team and the contribution from each member is recognised and valued equally. In general, rules and regulations are applied equally to all, irrespective of their hierarchical status in the organization.

In the developed world, all have to adhere to organisational values and norms, if they are to become culturally best-fit employees.

In foreign countries, the administrators want the public sector engineers to be a part of a multi-disciplinary team and work towards common goals. The socio-economic and socioengineering impacts of the decision making must be highlighted without placing undue emphasis on scientific reasoning.

Generally, Sri Lankan engineers are not only uncomfortable with this approach but have also got only a limited training in this area.

Sri Lankan engineers traditionally believe that what is important is the technical solution and that other aspects are of lesser importance. They expect others to accept technical solutions without questioning, being the professionals who are qualified to develop those solutions.

At the end of the day, the stakeholders would want to know what, why, when about the outcomes they get and also the level of social and financial impacts that the proposed solutions will have.

As a stakeholder, the community will not be ready to be permanently associated with any 
outcome, unless they are comfortable with it. Besides, they are the people who pay for the salaries of the engineers expecting the engineers to look after their wellbeing in an equitable and socially responsible manner.

If a migrant engineer fails to fulfil this role, that engineer would be seen as a professional who misfits the work culture and norms of the host country.

In countries like Australia, administrative systems, processes, standard operating procedures, safe work methods and codes of practice have already been developed and implemented, taking into account socioeconomic considerations. Hence, engineers who work within a particular administrative framework automatically meet the required performance standards making the stakeholders happy.

Only a very few Sri Lankan migrant engineers have mastered this technique. This is why the number of Sri Lankan engineers in foreign countries who are at the forefront of negotiations or customer interfaces is still very low.

For generations all around the world, engineers have been considered as professionals who make things to happen although they are poor communicators!

So, Sri Lankan engineers are entitled to their share of this generalisation, although our education system and the culture have given them more than a fair share.

Had engineers been good communicators, the world would have already known that half the successes of other professionals are a result of engineering inputs. Unfortunately, it has never happened that way.

Some Sri Lankan engineers are well known, internationally recognised technical analysts and the credit for this should go to the education system in Sri Lanka.

\section{Organised Cohesive Effort}

There have to be robust, well organised systems, processes and procedures in place at a workplace, for its staff to perform well. This allows the staff to ensure consistency in their approaches, fairness in their dealings and the certainty of predicted outputs. Also this allows the smooth transition of duties from one to another, when they are to be reallocated.

Just like the people who attempt doing a particular task repeatedly until it is done perfectly right, the administrative and regulatory systems currently in force in the foreign countries have been developed after many unsuccessful attempts.

The organisational set ups in the Western world have directly resulted from the efforts of dedicated professionals who had had untiring enthusiasm, and positive and persevering attitudes. Of course, the vital role played by good, governing administrators must also have to be recognised here.

Apparently, such cohesion and team work among professionals and administrators do not exist in Sri Lanka.

In Sri Lanka, there is organised chaos everywhere. What is most surprising is that no one appears to be concerned about it and that almost everyone opts to accept it as a fact of life.

It may be that chaos gives some undue power to take control over others and make a living. However, such chaos makes the country to remain standstill, in terms of public discipline, economic development and quality of life.

Unless someone is willing to divert this trend, the country would irrevocably lead to ultimate social and economic disintegration.

Although the country at present is progressing, though rather slowly, strategywise it is moving in different directions. High level strategic planning towards a common target is not in the agenda of the policy makers.

It is feared that at the pace the country is currently moving without a direction, the development gap between Sri Lanka and the developed countries could never be bridged.

If the current chaotic situation is allowed to flourish, it will be a breeding ground for substandard work, corruption and wastage.

The author however does not want to make any assertion that foreign systems are better than the existing Sri Lankan systems. 
Any country will have both a good and a bad side. Irrespective of the country from where they originate, there is no harm in promoting good things of a country.

Knowledge and operational tools are globally available and one must be ready to use whatever foreign tool that enables a better job.

The author's personal experience indicates that Sri Lankan public sector engineers do not even attempt to do what they can. There may be exceptions and instances of individual brilliance. Hence, it is worth to find out why they do not perform well, as a group in general.

It is easy to find fault with politicians and civil administrators to cover the mistakes of engineers. However, the author is of the view that engineers are equally answerable for their mistakes.

When a critic objectively criticises a movie, the movie director need not have to react by challenging the critic to direct a better movie. Movie director's job is to counter-respond with artistic facts to highlight the ideas that were behind his/her masterpiece. The same can be applied to engineers as well. The engineers should not blame politicians and administrators for their inability to give leadership and avoid mistakes.

Could engineers provide written evidence of any of their previous attempts at building transparent and robust systems and also on any such attempts that failed? Informal interactions with local engineers indicate that only a few can furnish such evidence. From these few engineers who were in a position to provide such evidence, the author inquired why they stopped without making fresh attempts as otherwise they could have been questioned why an alternative path with the same end result in mind was not taken.

Their usual excuses were built around their own predictions of inevitable failures, if they tried at them again.

This excuse has been given for many years.

One day, the next generation will ask these engineers what they had done to change the system rather than just blaming the system.
The author dares to say that engineers will not have credible answers to this question.

\section{Use of Skills to Lead the Pack}

Almost all engineers possess analytical skills acquired through their education and it is fair to say that they have well rounded skills on cost benefit analyses.

Engineers' analytical skill levels are also well above those of civil administrators and politicians because they have been well taught on research techniques.

So, it is fair to state that our engineers are able to develop well rounded arguments on the costs and benefits of having proper administrative and regulatory systems. Engineers can deliver a well argued business case on these to the decision makers at higher levels.

If an engineer fails to convince a politician or an administrator about the benefits of having a proper system, does this mean that the engineer has failed to sell the idea or that the politician or the administrator has failed to buy it?

Engineers' past failures were purely due to their inability to present their requests in a language the politicians and/or the administrators could understand and to convince the latter of the importance of their proposals.

Politicians are public representatives. They are receptive to public. Without any demand for them from the public, politicians cannot exist. Sri Lankan engineers should approach the issue tactically by identifying the public needs that are mutually beneficial to both the public and the engineers and by requesting the politicians to support their efforts through policy formulation and funding. Then, politicians will have no option but to agree to their proposals as otherwise the public would react negatively towards them.

So, the engineers must focus on what they can, rather than complaining on what they cannot.

\section{Different Thinking}

Engineering books are widely available for engineers to learn their chosen trade. Hence, their time and effort should be spent on 
developing practical tools and supporting documentation to apply what they already know.

Research organisations and university academics can continue with the robust analysis of engineering theories for the advancement of engineering technologies.

The author believes that only a fraction of the knowledge gained by engineers is converted into practical use at their respective work places. This lack of engineering applications by qualified engineers has prompted nonengineers to practice "engineering", especially in the private sector where professional regulations are not strictly adhered to.

The world has moved on and engineering theories have already been converted into standard guidelines, software models and tools. They are readily available for use. These models may not be perfect, but they will be good enough as tools for Sri Lankan engineers when carrying out their professional activities.

When the author recently visited a public sector organisation in Sri Lanka, he could see that project management records are kept manually without any order or clarity. Engineers could keep these records in soft form and monitor project progresses easily using widely available Microsoft software applications.

In other countries, it is a legal requirement to retain such records to be made use of in any future disputes related to liabilities.

The author does not believe that this is a resource issue but that it is related to attitudes and willingness to make tangible improvements to work processes.

The author has seen thousands of technical papers published in local engineering journals but is wondering how much of the content of those papers has contributed to the improvement of engineering activities on the ground. It is however not the fault of the writers but the engineers, as they do not make use of available technologies to develop practical applications.

It is important to pose a few questions to public sector engineers.

- Do you work sufficiently on things on which you already have full control?
- Does your team or unit or the organisation has a vision, mission and work plan?

- Do you have a set of organisational values?

- Are you convinced that your team members know the objectives of your team plan and that their individual roles are geared to achieve these objectives? If so, how can you prove it?

- Have you ever thought of doing your work differently to improve efficiency and effectiveness?

- What would happen to your team's performance when you are away from your work place?

- How do you ensure that your team members work with the same efficiency as when they are under your supervision?

If engineers can respond to the questions mentioned above, they would realise that there is a need for a radical change in their thinking.

\section{The Perception and the Reality}

To do the right work in the right way, the public sector engineers will have to first shed their own "expert" tags and show willingness to learn from others.

Simply saying, we have not yet become the "experts". However, we are GOOD ENOUGH for the task in hand.

Sri Lanka is a tiny island with almost no influence on the rest of the world. Our universities are at the bottom half of the university rankings of the world and Asia. However, they are good enough for producing the type of engineers the country needs.

The IESL corporate membership, which is an indicator of our professionalism, is not recognised even by certain Asian countries, but is sufficient for us to practice as engineers.

So, while accepting the reality, everyone must appreciate the ADEQUACY of their qualifications at this point of time.

\section{Systems View and Business Excellence Framework}

Sri Lankan engineers are capable of fulfilling their immediate needs if sufficient management 
guidance is given. So, they must be ready to accept help from outside.

Around the world, there are many best practices that have already been tested and implemented.

Often engineers are appointed as heads of Sri Lankan public sector entities or at least as divisional heads. As executive officers, they are responsible for carrying out periodic checks on the performance of their organisations. They must know the activities that are being done well and the activities that are not being done so well. Most importantly, they need to know what they have to do to improve organisational performance.

Public organisations are live and dynamic. Services are delivered to the community through organisational systems built upon relationships. These relationships are built around internal staff, community and service providers.

Within an organisation, there are systems and subsystems. The performance level of an organisation depends on how well its systems and subsystems have been formulated. The role of the senior management is to analyse the activities of the organisation, both critically and holistically. This leads to the development of systems and subsystems. The synchronised operation of organisational systems and subsystems is essential to achieve the strategic targets of an organisation.

The system view will encompass the following elements whatever the management level is:

- Values

- Vision

- Mission

- Stakeholders

- Inputs

- Suppliers

- Outputs

- Customers

- Performance Measurements

- Internal Staff

- Processes

- Process Measures

- Assets

- Feedback

In large organisations, system views have to be developed from top to bottom. All systems and subsystems should fall into the overall organisational system like a completed jigsaw puzzle.

Each and every wheel of the organisational system must be appropriately sized and set in motion towards the organisation's strategic direction. Otherwise, system breakdowns will be inevitable affecting service delivery.

This is a step by step process. The senior management must develop the organisational level 'Systems View' and the middle management must be directed to develop subsystem views for each division. Finally, the operational staff will have to get involved in the process mapping and the development of standard operating procedures.

The aim of all aforementioned work is to achieve "Organisational Excellence".

There are a few internationally recognised "Organisation Excellence Frameworks" being practiced. The author has personal experience in the practical application of Australian Business Excellence framework ${ }^{1}$.

Australian Business Excellence Framework ${ }^{1}$ is an internationally recognised quality standard. The main elements of this framework are being introduced to the Australian public sector gradually to improve its efficiency, effectiveness of service delivery and responsiveness to the public.

The Australian Business Excellence Framework considers following elements:

- Leadership

- Strategy and Planning

- Data, Information and Knowledge

- People

- Customer and Market Focus

- Innovation

- Quality and Improvement

- Success and Sustainability

The idea is to audit all organisational activities under each of the above mentioned elements and identify the deficiencies and conflicts. Thereafter an improvement plan will be developed and implemented.

Periodic auditing has to be done to check the progress of the implementation of the quality improvement plan. 
Up to now, the public sector in Sri Lanka has been engaging the services of foreign consultants to introduce major quality improvements to their organisations. This is usually done without making an initial analysis to identify what is really needed. That analysis must be done by local engineers.

This is why the foreign sponsored major organisational reforms have so far failed and the quality of the service delivered by public sector organisations still remains at a record low.

Before appointing foreign consultants to induce efficiency enhancement drives, local engineers have to first do what they can, possibly with the help of Sri Lankan engineers based overseas who have had the exposure to better administrative and regulatory systems. Once an organisation is ready with the basic administrative framework, foreign assistance can be sought to make more rigorous quality improvements.

\section{Role of Engineering Executive Officers}

All engineering divisional heads need to develop at least a set of organisational values, and mission and vision statements for their business units with the involvement of their operational staff.

The heads must direct the middle management to develop team plans outlining the roles of each team, duties and activities and the short term and long term targets. These team plans must be supported with processes and procedures. There should be a lively discussion and agreement on how the activity records should be kept in the organisations concerned to ensure that information is accessible to all when needed.

The divisional heads should do improvements in the areas on which they have full control. By doing so, they will be able to influence even the areas on which they do not currently have any control.

The engineers should encourage politicians to borrow from overseas effective tools, concepts and methodologies. After borrowing these products, engineers can re-configure them to suit the local requirements.
The engineers must convince politicians on what is needed to make engineering services look more professional and effective and about the benefits that the public will receive by doing so.

Then, politicians would sell this suggestion to the public as if it is one of their own initiatives. Let that be because it will be beneficial for the engineers as well as for the engineering profession.

Politicians as it happens now will otherwise, either decide on the wrong product unilaterally, or else, greedy multinational business agents will dump wrong products on engineers' laps through gullible politicians.

Foreign countries have already done the hard yards. Engineers should reap direct benefits from the products other countries have made.

\section{Role of the IESL}

At times, public sector engineers face 'brick walls' preventing them from moving forward with their proposals. The IESL needs to support public sector engineers by advising them to refine their proposals making use of the engineering knowledge of other members. Then, the IESL as the professional authority should take forward the proposal to the community.

The proposal has to be presented to the community in a form that can be easily understood.

In that way, public pressure can be generated upon politicians to act on proposals.

Hence, public service engineers should have a continuous dialogue with the IESL about their endeavours.

The IESL should form a Professional Forum and facilitate Sri Lankan engineers based overseas to conduct voluntary training programs and organisational development programs to help public sector engineers to develop organisational management structures.

In essence, all parties should work together towards one goal; the efficient and effective delivery of engineering services to the public. 


\section{Concluding Remarks}

Sri Lankan professionals have a habit of doing the same activity same way, over and over again, expecting an improved outcome.

It does not work that way.

If different outcomes are to be obtained, there need to be a change in the actions. There are many Sri Lankan engineers working overseas who have previously worked in the Sri Lankan public sector. They have a wealth of experience in varied subject areas with which they can come to the help of local engineers.

At the end of this process, local engineers can pass over the knowledge they acquire, to the younger generations of engineers in Sri Lanka as well.

The IESL would be the ideal professional authority to guide them all and make this a reality.

\section{References:}

1. GB 002-2011; The Australian Business Excellence Framework;

ISBN: 192109360

Source:

http:/ /infostore.saiglobal.com/store/Deta ils.aspx?productID=1499769 